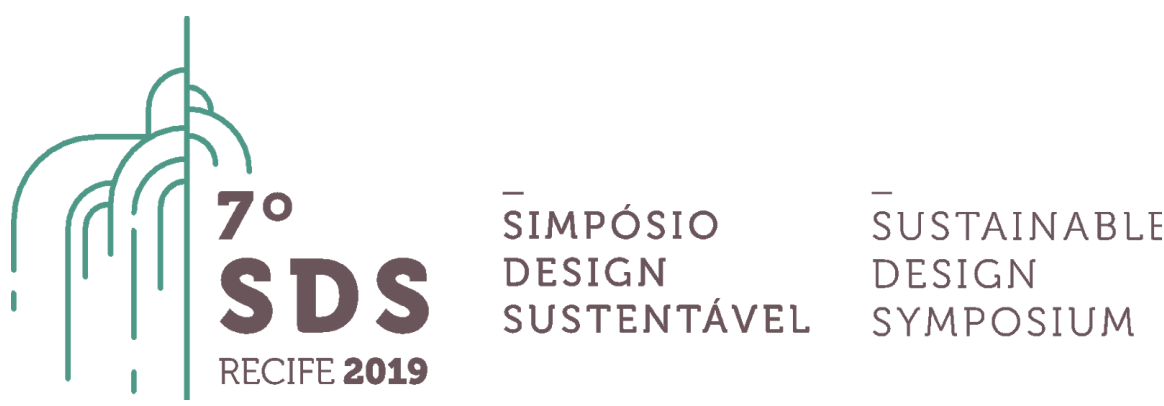

\title{
Design para a inovação social: ações de valorização da identidade territorial e cultural de comunidades remanescentes quilombolas
}

\author{
Gabrielle Pinto Borges ${ }^{1}$, Dr. a Carolina luva Mello² e Dr. José Marcos Froehlich ${ }^{3}$ \\ ${ }^{1}$ Universidade Federal de Santa Maria, estudante de Desenho Industrial, gabriellepborges@gmail.com \\ ${ }^{2}$ Universidade Federal de Santa Maria, Departamento de Desenho Industrial, carolinaiuva@gmail.com \\ ${ }^{3}$ Universidade Federal de Santa Maria, Departamento e PPG em Extensão Rural e PPG em Ciências Sociais, \\ jmarcos.froehlich@gmail.com
}

\begin{abstract}
Resumo. Este artigo apresenta uma reflexão sobre o design para a inovação social a partir de uma experiência extensionista que aproximou acadêmicos da Universidade Federal de Santa Maria das Comunidades Remanescentes Quilombolas de Júlio Borges (município de Salto do Jacuí, Rio Grande do Sul) e Linha Fão (município de Arroio do Tigre, Rio Grande do Sul). Por meio de uma metodologia participativa, apresentam-se ações que buscam valorizar a identidade territorial e cultural quilombola, como o processo de construção coletiva de uma identidade visual que vincula a produção artesanal das comunidades como sendo quilombola. Ressalta-se a importância da inserção do designer em comunidades que se encontram em situação de vulnerabilidade social, especialmente no sentido de contribuir para que inovações sociais $e$ soluções criativas sejam desenvolvidas para os problemas que eles enfrentam diariamente.
\end{abstract}

Palavras-chave. Inovação Social; Design; Identidade territorial; Identidade cultural; Comunidade; Quilombola.

\section{Design para a inovação social e comunidades remanescentes quilombolas}

Este artigo surge da aproximação do curso de Desenho Industrial da Universidade Federal de Santa Maria das Comunidades Remanescentes Quilombolas de Júlio Borges (Salto do Jacuí, RS) e Linha Fão (Arroio do Tigre, RS), por meio de um projeto de extensão, construindo assim um processo de troca de conhecimentos entre sociedade e universidade que possibilita 0 fortalecimento de experiências locais, em um contexto de inovação social e valorização da identidade territorial e cultural quilombola. O projeto conta com a colaboração do Núcleo de 
Pesquisa e Extensão em Desenvolvimento Territorial (NEDET) Centro Serra. Os NEDETs são equipes técnicas formadas por professores e pesquisadores de instituições públicas de ensino superior que realizam, nos Territórios Rurais, ações de extensão e pesquisa, envolvendo o assessoramento, acompanhamento e monitoramento das políticas públicas de desenvolvimento rural e de inclusão produtiva (NEDET CENTRO SERRA, 2017).

Segundo Manzini (2017), o design para a inovação social busca inovações significativas baseadas em novas relações sociais e novos modelos econômicos não excludentes, ativando o desenvolvimento de alianças e redes, bem como a integração de ações no território, sendo essenciais para fortalecer e empoderar as comunidades, valorizar os seus produtos e serviços, equilibrando a tradição e o patrimônio cultural com a inovação tecnológica. Ainda para Manzini (2008), o termo inovação social refere-se a mudanças no modo como indivíduos ou comunidades agem para resolver seus problemas ou criar novas oportunidades e são guiadas mais por mudanças de comportamento do que por mudanças tecnológicas ou de mercado, geralmente emergindo através de processos organizacionais 'de baixo para cima' em vez daqueles 'de cima para baixo'.

Os indivíduos, no caso relatado neste artigo, são as pessoas que compõem as duas comunidades rurais remanescentes quilombolas, descendentes de escravos fugidos que identificaram na região um lugar de difícil acesso, propício para resistir e sobreviver. Com a escravidão, o povo negro teve sua cultura brutalmente inferiorizada, dificultando a reprodução de sua identidade social e cultural. Em contraponto, os quilombos são símbolos de resistência, e seus remanescentes têm buscado na atualidade o direito à uma vida digna e a valorização de suas especificidades culturais.

Os quilombos atualmente caracterizam-se como comunidades tradicionais, por compreender que sua relação com a terra não é atrelada a posse, mas sim as questões de identidade. Também se destacam por ter culturas distintas da majoritária, sempre em ameaça devido a invisibilização social do processo histórico da escravidão e da marginalização da identidade negra (VATTATHARA, 2018, p.20).

A Comunidade Remanescente Quilombola Linha Fão está situada no quinto distrito do município gaúcho de Arroio do Tigre, chamado de Sítio Novo, na região noroeste distante cerca de 30 quilômetros da sede. Ocupa uma área de 11 hectares cuja distribuição se deu com as regras de transmissão de herança. As 25 famílias que compõem a Comunidade Quilombola possuem certo grau de parentesco. Em virtude de metade da área que ocupam não ser propícia para agricultura, pois está em um terreno íngreme e com muitos sedimentos rochosos, vivem praticamente do trabalho nas lavouras de fumo do município, ou de serviços temporários diversos, no período da entressafra dessa cultura (FROEHLICH, 2017).

A Comunidade Remanescente Quilombola Linha Fão é reconhecida pela Fundação Palmares desde 2006 e pelo Governo Federal desde 2007. Conforme Rubert (2005), as terras foram conquistadas através de uma permuta ocorrida há cerca de 35 anos entre Belmira Xavier, mulher negra e viúva, e um colono alemão. As famílias, além de se dedicarem à produção de artesanato para complemento da renda, também plantam na área a eles destinada e eventualmente arrendam terras de lindeiros. É também muito comum que trabalhem como peões, diaristas ou agregados (RUBERT, 2005). A comunidade apresenta um estado de vulnerabilidade social muito acima da média municipal, especialmente por viverem em uma extensão territorial de apenas 11 hectares (as 25 famílias), quando a média no município é de 20 hectares/família, e apresentarem uma renda per capita mensal de R\$ 600,00/família, devendo ser considerado que a maior parte deste montante é conseguida na época em que trabalham na colheita do fumo, de novembro a março. Tal situação histórica de precariedade e vulnerabilidade 
fez a comunidade lançar mão de estratégias de sobrevivência, recorrendo à migração para o município vizinho de Salto do Jacuí, mais propriamente para Júlio Borges, cerca de 10 quilômetros de distância de Linha Fão, para trabalharem na catação (extração) de pedras ágatas naquele sítio (FROEHLICH, 2017).

Com a contínua migração dos remanescentes de quilombos para Júlio Borges foi se constituindo a Comunidade Remanescente Quilombola de Júlio Borges, a qual ainda mantém com Linha Fão fortes laços de parentesco por consanguinidade e afinidade. Recentemente a política de titulação do Estado reconheceu e titulou área de 442 hectares à comunidade quilombola de Júlio Borges, mas as 40 famílias do território só conseguiram ocupar 221 hectares, nos quais realizam diversas atividades econômicas como artesanato, agroindústria de panificados, cultivo de soja e de subsistência (QUADROS, 2015).

Portanto, ambas as Comunidades Remanescentes Quilombola possuem a presença de uma cultura baseada em saberes tradicionais, que remontam a seus antepassados africanos escravizados no Brasil e seus descendentes. Além disso, são comunidades pobres, com poucos recursos financeiros e sociais, fato que as colocam à margem dos interesses das demais esferas da sociedade. $O$ designer pode se inserir de forma participativa neste contexto e somar com seu conhecimento projetual aos saberes tradicionais dessas comunidades, fomentando a valorização da identidade cultural. Fortalece desta forma, a autogestão e organização da comunidade por ela mesma, fazendo um movimento de 'baixo para cima' que modifica as estruturas sociais e traz novas perspectivas de condição de vida para essas pessoas.

\section{Metodologia participativa e emancipatória}

A abordagem requerida pelo design para a inovação social é a participativa, onde os designers atuam como facilitadores no processo de busca de soluções para os problemas das comunidades, envolvendo seus membros no processo de criação e desenvolvimento projetual sem deixar de levar em consideração seus conhecimentos, capacidades e necessidades locais. Portanto, desenvolver um projeto que trabalhe a valorização de identidades territoriais precisa, além de reunir referenciais locais e aplicá-los em produtos para posterior comercialização, promover diálogo com os agentes locais para que a ação seja eficiente e coerente com a sua realidade (MELLO, et al., 2011). O diálogo, então, configura-se como o método de relação entre os sujeitos, as diversas partes se encontram em permanente interação (FREIRE, 2006).

Do ponto de vista metodológico, o projeto de extensão que permitiu a aproximação dos acadêmicos do Desenho Industrial às comunidades quilombolas é uma pesquisa-ação, pois "visa desvendar um leque aberto composto de possibilidades de ação progressivamente descobertas, formuladas ou escolhidas pelos grupos que participam ativamente no processo" (THIOLLENT, 1997, p. 25). Segundo Thiollent (1997), uma pesquisa-ação envolve as seguintes fases: Fase exploratória (diagnóstico para identificar um problema); Fase principal (planejamento da ação, considerando as ações como alternativas para resolver o problema); Fase de ação (execução das ações, com seleção de um roteiro de ações); Fase de avaliação (avaliação das consequências da ação). Às fases da pesquisa-ação propostas por Thiollent (1997) foram acrescentadas as oito ações para valorizar os produtos locais propostas por Krucken (2009): Reconhecer as qualidades do produto e do território; Ativar as competências situadas no território; Comunicar o produto e o território; Proteger a identidade local e o patrimônio material e imaterial; Apoiar a produção local; Promover sistemas de produção e de consumo sustentáveis; Desenvolver novos produtos e serviços que respeitem a vocação e valorizem o território; Consolidar redes no território;

À partir das primeiras fases da pesquisa-ação, que possibilitou o contato dos acadêmicos com as comunidades, foram definidas algumas demandas mais urgentes, como a necessidade de desenvolver participativamente uma identidade visual (marca coletiva) que identifique e diferencie os produtos das comunidades Linha Fão e Júlio Borges em relação a similares, 
desempenhando o papel de um dispositivo de reconhecimento do trabalho e da identidade comunitária quilombola.

Haja vista que a metodologia proposta é circular e não linear, algumas etapas se complementam e se sobrepõem. Quando se está comunicando o produto ao território, por exemplo, já se está ativando as suas competências, bem como apoiando a produção local. Ressalta-se, portanto, que o projeto ainda está em andamento e que algumas fases da metodologia ainda estão em desenvolvimento. Desse modo, o presente artigo está delimitado a expor duas das ações de valorização da produção artesanal que contemplaram as comunidades, uma que se refere a comunicação entre o produto artesanal e a identidade quilombola e outra que se refere ao processo de construção da identidade visual da comunidade quilombola de Júlio Borges, que está em processo mais avançado de construção.

\section{Ações de valorização da identidade territorial}

A atuação do design em prol da valorização da cultura e dos aspectos identitários dos territórios possui potencial de impulsionar a geração de renda, pois favorece as potencialidades territoriais e auxilia na melhor comunicação dos produtos aos seus potenciais consumidores.

Estimular o reconhecimento das qualidades e dos valores relacionados com um produto local - qualidades referentes ao território, aos recursos, ao conhecimento incorporado na sua produção e à sua importância para a comunidade produtora - é uma forma de contribuir para tornar visível à sociedade a história por trás do produto. Contar essa "história" significa comunicar elementos culturais e sociais correspondente ao produto, possibilitando ao consumidor avaliá-lo e apreciá-lo devidamente. E significa desenvolver uma imagem favorável do território em que o produto se origina (KRUCKEN, 2009, p.22).

Nesse contexto, o principal papel do designer é facilitar e apoiar o desenvolvimento de inovações nos grupos sociais que atua, podendo ser considerado um 'especialista de projeto' que coordena uma rede complexa de atores que pode envolver empresas, instituições, entidades locais, associações não governamentais, usuários finais, entre outros (KRUCKEN, 2009).

A dimensão cultural e o saber-fazer expressados na criação de artefatos muitas vezes não são comunicados de forma explícita nos produtos. Informar sobre o 'modo de fazer tradicional', por exemplo, é importante para a valorização e a perpetuação da tradição e da história dos produtos, distinguindo e exaltando as comunidades que os produzem e seus respectivos patrimônios culturais. Desta forma, as ações de extensão são fundamentais para promover o desenvolvimento do território e construir, a partir da interação entre diversas áreas do conhecimento, uma nova proposta de atuação dos desenhistas industriais na sociedade: ser capaz de promover soluções inovadoras junto a comunidade, beneficiando os atores que a compõe.

No caso apresentado neste artigo, as atividades promovidas pela área do design foram somadas às outras ações extensionistas que vêm sendo promovidas pelo NEDET Centro Serra, como atividades de mobilização, oficinas diversas, visitas à outras experiências comunitárias e capacitações. O NEDET Centro Serra vem atuando desde 2016 junto às comunidades quilombolas de Júlio Borges e Linha Fão em ações de gestão social e inclusão produtiva com vistas a superação do estado de vulnerabilidade social (FROEHLICH et al, 2019).

\subsection{Comunicação entre o produto artesanal e a identidade quilombola}

As mulheres quilombolas das comunidades em questão, confeccionam artefatos artesanais para comercialização, porém há pouca representação da identidade quilombola nos produtos finais. Nesse sentido, a atuação do design pode ter papel fundamental para que a comunidade passe a reforçar a sua especificidade identitária na sua produção artesanal, valorizando suas 
práticas sem perder sua originalidade. Como apontado por Borges (2003), o design pode promover uma 'abertura de olhos', transcendendo o estético para alcançar o melhor das matérias-primas locais e a otimização dos processos produtivos.

Entre as primeiras ações promovidas pelo NEDET Centro Serro com o intuito de reconhecer a produção artesanal das moradoras das comunidades, ressalta-se o levantamento fotográfico dos produtos (Figura 5) e entrevistas informais sobre as técnicas e motivos utilizados nas peças. É importante ressaltar que as técnicas são passadas de geração em geração por história oral, desta forma os ensinamentos são passados das anciãs principalmente para as jovens da comunidade. Como o relato de uma das mulheres quilombolas, exemplifica:

Agora ela tá aprendendo né a fazer os artesanato. Eu não vou tá aqui pra sempre e é importante que ela saiba se virar sozinha sem perder todos os costumes, agora com esses internet e celular fica difícil os jovens querer aprender coisa com os velhos. Mas não fui nem eu que puxei ela pra aprender, ela que me procurou pra aprender e mostrar na escola, toda noite a gente senta e faz junto alguns artesanatos (AMARA, fragmento de entrevista). (VATTATHARA, 2018, p.34).

Figura 5 - Artesanato das artesãs da Comunidade Quilombola Linha Fão

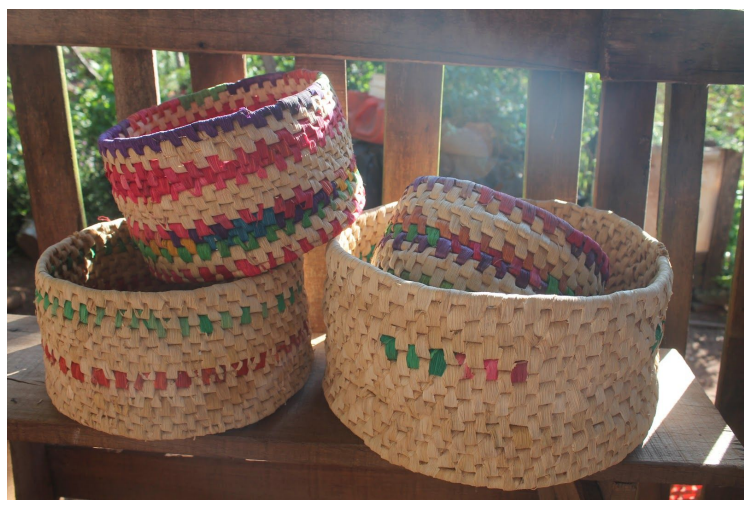

Fonte: acervo do NEDET CS

A partir do levantamento realizado, o NEDET Centro Serra organizou um encontro na comunidade de Linha Fão com o intuito de iniciar discussões sobre o tema do artesanato (Figura 6). O encontro visou realizar uma troca de saberes das técnicas entre as comunidades e instigar a percepção da importância da valorização do artesanato quilombola.

Figura 6 - Encontro sobre artesanato na Comunidade Quilombola Linha Fão

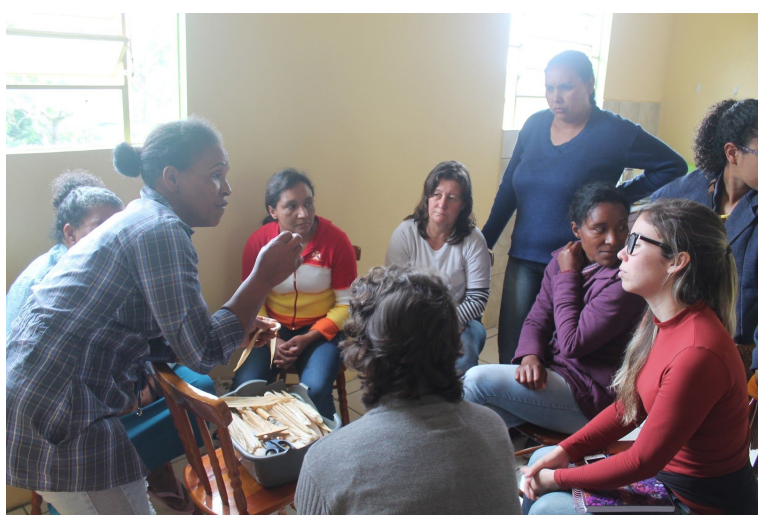

Fonte: acervo do NEDET CS 
O desenvolvimento da produção local deve conjugar tradição e inovação, o design pode contribuir muito nessa tarefa, valorizando o saber-fazer tradicional e buscando formas de incorporar novas tecnologias e possibilidades de projeto sem descaracterizar a identidade do produto e do território. Além disso, ao difundir valores relacionados com a sustentabilidade, o designer pode estimular um posicionamento mais ativo e consciente do consumidor em suas escolhas, um dos principais desafios, sob esta perspectiva, é trazer visibilidade aos serviços ambientais envolvidos no uso sustentável dos recursos naturais e também promover espaços de conversa e integração que somam no processo de criação junto às comunidades.

Um dos pontos chave é a consolidação de redes no território, assim os atores se motivarão a trabalhar de forma conjunta, produzindo valor e qualidade (e não apenas comercializando bens físicos). As redes são também importantes porque promovem a renovação das estratégias de gestão e de organização do território, e tem como objetivo que as comunidades tenham autonomia e possam continuar produzindo e gerando sua própria renda sem a necessidade de intervenção de terceiros. Nesse sentido, as comunidades tiveram a oportunidade de participar com seus produtos artesanais e produtos da terra, em julho de 2018, da FEICOOP (Figura 7), Feira Internacional do Cooperativismo e da Economia Solidária, na cidade de Santa Maria, Rio Grande do Sul. Trata-se de uma ação contínua com o objetivo de promover a geração de trabalho e renda para combater a pobreza e desigualdade social (FEICOOP, 2019).

Figura 7 - Mulher quilombola expondo seus trabalhos artesanais na FEICOOP

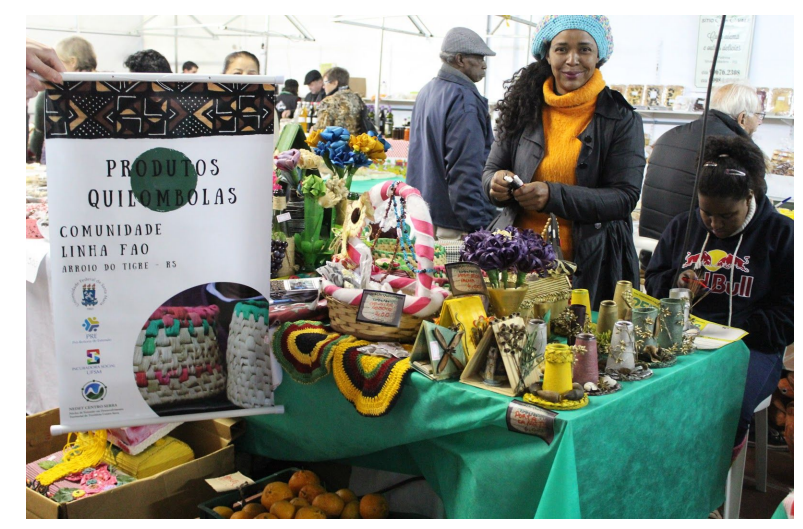

Fonte: acervo do NEDET CS

Avaliando a participação das comunidades na Feira as lideranças das duas comunidades afirmaram que o importante não era a venda dos produtos no evento, nem sequer o dinheiro arrecadado, mas sim a saída da invisibilidade. Afirmaram que antes os quilombolas eram invisíveis, que ninguém entendia que a comunidade remanescente de quilombos produzia alimentos, cultura e tradições. Em sua opinião, o verdadeiro saldo da participação no evento foi poder expor seus produtos para a comunidade externa, de igual para igual, sendo valorizados pelas características que sempre lhe foram conotadas como algo a ser marginalizado, afastado e esquecido. (VATHATTARA, 2018, p. 44)

Após a participação dos grupos na FEICOOP, notou-se saldos positivos, entre eles a valorização do trabalho quilombola, a boa autoestima dos sujeitos e também o reconhecimento percebido pelos mais jovens, o que é crucial para que desperte o interesse pelo aprendizado das tradições artesanais e por conseguinte, a perpetuação da identidade quilombola. Também foi notado que na feira, bem como em outros espaços de comercialização, fazia falta uma identidade visual para as comunidades, para identificar e classificar os produtos como quilombolas, bem como para dar visibilidade à comunidade. A criação desta identidade está sendo elaborada por 
meio de uma metodologia participativa, e os resultados parciais alcançados até o momento serão apresentados na próxima sessão.

\subsection{Construção da identidade visual da Comunidade Remanescente Quilombola Júlio Borges}

A partir das ações promovidas pelo NEDET Centro Serra nas comunidades, como ressaltado anteriormente, percebeu-se a necessidade da criação uma marca coletiva que contribuísse para o fortalecimento das identidades sociais e culturais dos atores e que facilitasse o reconhecimento da produção artesanal dos grupos como sendo de origem quilombola. Assim, deu-se início ao processo de criação de uma identidade visual para a Associação Comunitária Quilombola de Júlio Borges $^{1}$.

Na primeira etapa do processo, foi ministrada pela estudante extensionista uma oficina de experimentação gráfica com o intuito de compreender as palavras, imagens e símbolos que representam a comunidade para as pessoas que ali moram (Figura 1). A oficina teve em média 15 participantes, maioria mulheres adultas, jovens e idosas.

Figura 1 - Oficina de experimentação gráfica

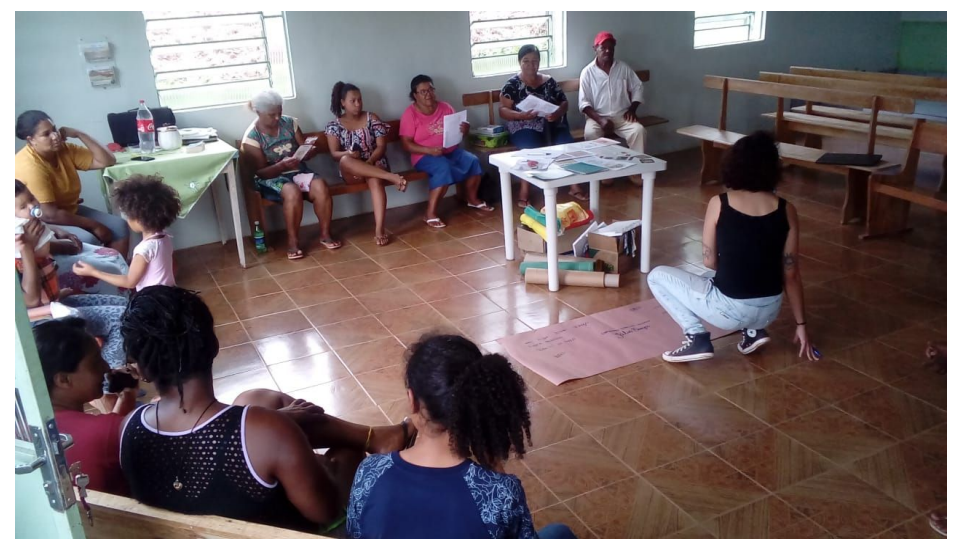

Fonte: acervo do NEDET CS

A primeira parte da metodologia da oficina começou com uma introdução sobre importância de se ter uma identidade visual para associação comunitária e a relevância de identificar as produções da comunidade como sendo quilombolas. Foram apresentadas também, exemplos de marcas quilombolas já existentes e a partir do interesse do grupo por uma ou outra já se pode direcionar a expressão que a comunidade gostaria que a sua marca tivesse.

Já a segunda parte da oficina teve início com um brainstorming, técnica frequentemente usada para desenvolver novas ideias ou projetos, para juntar informações e para fomentar o pensamento criativo de um grupo. Foram feitas perguntas para estimular os participantes a falarem palavras que representassem a comunidade. Entre as palavras, destacam-se: família, seus valores (amor, proteção, núcleo) e os sujeitos da comunidade, a mulher e o homem quilombola (trabalhadores), as crianças (esperança), jovens (mudança) e os idosos (sabedoria); o trabalho (dignidade) e suas ferramentas, em especial a enxada; o plantio e produtos da terra, ervas, legumes e o valor do seus alimentos e por fim os diferentes tipos de artesanato (passados de geração em geração). Após conhecidos os principais eixos da expressão da comunidade foram feitos vários desenhos pelas participantes (Figura 2), expressando essas palavras não só oralmente, mas também graficamente.

\footnotetext{
${ }^{1}$ Ressalta-se que a identidade visual para a Associação Comunitária Quilombola Linha Fão ainda está em processo de desenvolvimento, e por esse motivo não foi retratada neste artigo. 
Figura 2 - Desenhos feitos pelos participantes da comunidade

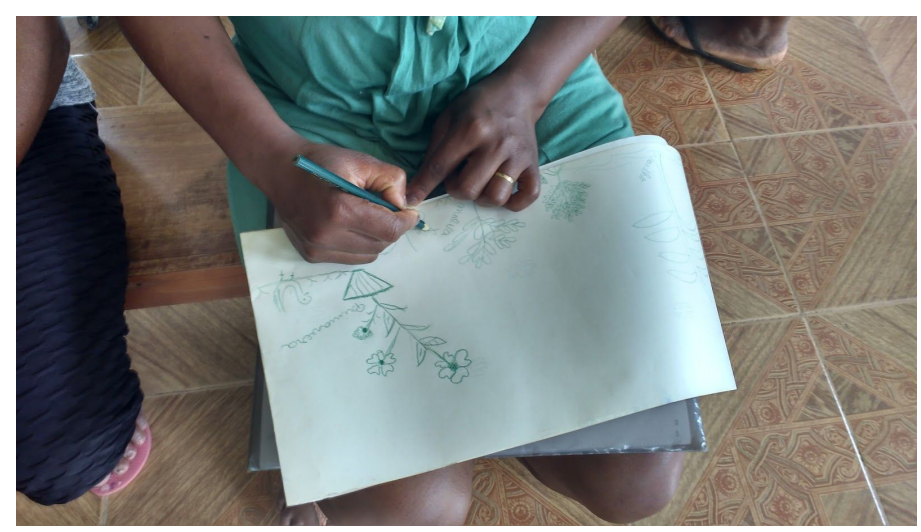

Fonte: acervo do NEDET CS

Após o espaço de criação e troca com a comunidade foi possível obter várias referências gráficas digitalizadas que foram desenhadas pelos presentes na oficina (Figura 3), como a frase 'Sou mulher. Sou quilombola. Sou vencedora!' e a representação da horta existente na comunidade, com as mulheres próximas, demonstrando o contato da mulher negra quilombola com o cultivo de produtos da terra. Estes desenhos, assim como as palavras ditas, nortearam os próximos processos da projetação da identidade visual da associação comunitária.

Figura 3 - Referências gráficas digitalizadas

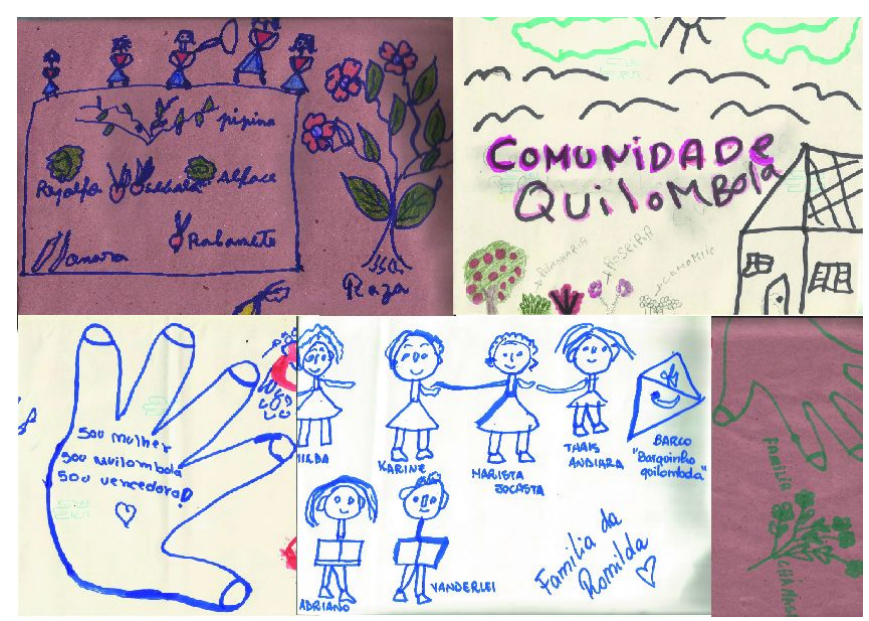

Fonte: acervo do NEDET CS

Posteriormente, foram criadas diversas opções de identidades visuais através dos elementos que saíram da oficina. Buscou-se manter contato direto com as comunidades no processo de criação da identidade visual, estabelecendo um diálogo aberto entre a criação e os beneficiados, conforme prontas as ideias eram apontadas alterações por parte da comunidade. A identidade visual (Figura 4) está em processo de finalização e foi escolhida em consenso entre os e as moradoras da comunidade de Júlio Borges. 


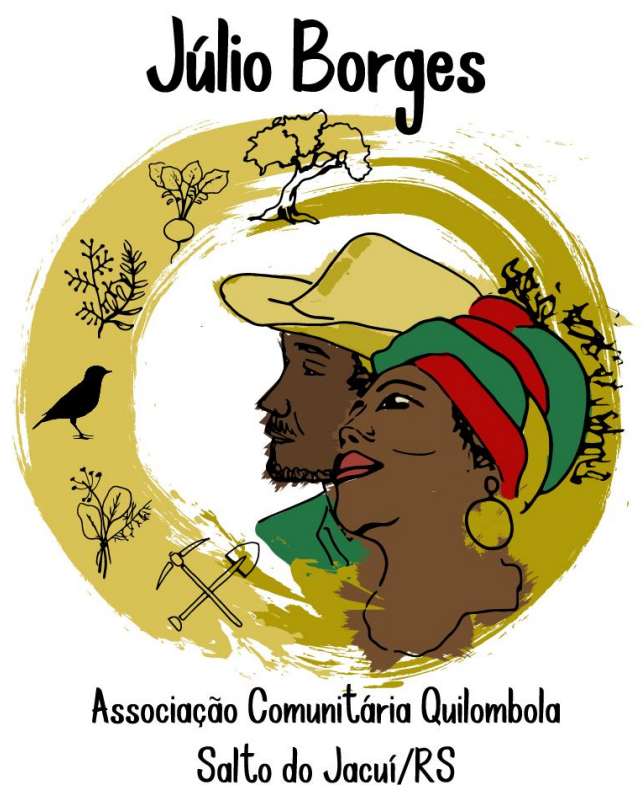

Fonte: acervo do NEDET CS

A identidade visual é marcada pela presença de diversos elementos da cultura quilombola, como as ferramentas de trabalho, a natureza, as ervas medicinais, os produtos da terra e os animais. Como ponto central da identidade apresenta-se a figura de uma mulher negra altiva com seu turbante e do homem negro quilombola, ambos trabalhadores e provedores da sustentabilidade da comunidade. Destaca-se o importante papel da mulher quilombola na comunidade: educam as crianças de forma colaborativa, trabalham na lavoura e nas casas próximas no território, fazem a manutenção das relações sociais, são as participantes mais ativas nas atividades extensionistas promovidas na comunidade e são as principais responsáveis pela passagem da história oral da comunidade, mantendo viva a identidade quilombola em um movimento de resistência.

\section{Conclusões e novas perspectivas}

Como previamente ressaltado, a dimensão cultural e o conhecimento expressados na criação de artefatos muitas vezes não são comunicados de forma explícita nos produtos, informar sobre o 'modo de fazer tradicional', por exemplo, é importante para a valorização e a perpetuação da tradição e da história dos produtos, distinguindo e exaltando as comunidades que os produzem e os territórios de origem. Portanto, é notável o potencial que a inserção de designers em comunidades que vivem em situação de vulnerabilidade social possui de construir, conjuntamente aos atores, inovações sociais e soluções criativas para os problemas enfrentados por eles diariamente. $E$ é neste sentido que o presente projeto de extensão vem atuando, aproximando estudantes da sociedade em um contexto de inovação social.

A parceria entre universidade e as comunidades, por meio de ações extensionistas, vem demonstrando resultados e benefícios sociais, como visibilidade da identidade negra e a maior valorização da identidade quilombola, o que gera orgulho e reconhecimento dos atores, como sujeitos políticos e ativos na sociedade. A identidade do indivíduo liga-o a um coletivo e produz o sentimento de pertencimento (HALL, 2006). Esse sentimento está fortemente presente nas Comunidades Remanescentes Quilombolas, ainda que em processo de construção, como demonstra uma das moradoras da comunidade Júlio Borges: 
Eu sou quilombola com muito orgulho. É um orgulho pra nós, temos que assumir o quilombola. Esses dias fui fazer a consulta em Sobradinho e a mulher me olhou assim né e ela perguntou assim pra mim - que geração tu é? - e eu respondi que sou é quilombola com muito orgulho e bato no peito. Tem que dizer mesmo, é isso que somos e é assim que existimos. (VATHATTARA, 2018, p. 43)

Acredita-se no poder da troca de saberes como ferramenta emancipatória da comunidade, a metodologia participativa para além de unir as pessoas da comunidade para criar a partir de uma oficina, uma identidade visual ou um artefato, principalmente proporciona um espaço de lazer, fora da rotina, onde se tem a oportunidade de refletir sobre a comunidade quilombola, quem são seus indivíduos, quais são seus direitos, como é seu território, qual é sua identidade. Desta forma, fomentando pensamentos críticos que entendam as relações sociais e econômicas, assim como que valorizam as criações artesanais e cultivos da terra que reafirmam a cultura quilombola, fortalecendo a comunidade e apresentando aos jovens uma nova perspectiva de vida.

Ao fazer com que a produção artesanal dos grupos também ressalte esta identificação positiva com o território, possibilita-se uma maior valorização dos produtos nos mercados em que atuam, podendo resultar em maiores retornos econômicos. Assim, a criação de identidades visuais que identificam as associações comunitárias e os produtos como sendo quilombolas pode contribuir para uma maior geração de renda, fundamental para a autonomia e autogestão das comunidades, fazendo com que se voltem ao seu território e façam dele seu sustento, criando-se novas redes de comércio colaborativo. $O$ projeto está em andamento, e ainda há muito o que ser construído desta parceria, como a consolidação das identidades visuais comunitárias e o fortalecimento das redes colaborativas. Porém, já é possível afirmar que os resultados, mesmo que parciais, são positivos tanto para as comunidades quanto para os acadêmicos envolvidos, reforçando a importância da troca de saberes entre universidade e sociedade.

\section{Referências}

BORGES, A. Designer não é personal trainer: e outros escritos. 2 ed. São Paulo: Edições Rosari, 2003.

FREIRE, P. Pedagogia da esperança: um reencontro com a Pedagogia do oprimido. São Paulo: Paz e Terra, 2006.

FROEHLICH, J. M. Produção e gestão quilombola em empreendimentos econômicos solidários no território centro serra do RS: mediações e tecnologias sociais em contextos de interculturalidade. Projeto contemplado com chamada CNPq/MTb-SENAES 27/2017.

FROEHLICH, J. M. et al. Do NETED à incubação: Trajetória das ações de extensão universitária no âmbito da abordagem territorial do desenvolvimento. Revista Conexão UEPG, v. 15, n. 2, p. 135-141, 2019.

FEICOOP. $26^{\circ}$ FEICOOP. Santa Maria. 2019. Disponível em: <https://www.esperancacooesperanca.org/copia-especial-25-anos>. Acesso em 19 abril. 2019.

HALL, S. A identidade cultural na pós-modernidade. 11aㅡ Ed. Rio de Janeiro: DP\&amp;A, 2006.

KRUCKEN, L. Design e território: valorização de identidades e produtos locais. São Paulo: Studio Nobel, 2009.

MANZINI, E. Design para a inovação social e sustentabilidade: comunidades criativas, organizações colaborativas e novas redes projetuais. Rio de Janeiro: E-papers, 2008.

MANZINI, E. Design: quando todos fazem design: uma introdução ao design para a inovação 
social. São Leopoldo, RS: Ed. UNISINOS, 2017.

MELLO, Carolina luva de. et al. Projeto Design Social: geração de renda e resgate cultural através do design associado ao artesanato. Inclusão Social, v. 5, n. 1, 2011. 17

NEDET CENTRO SERRA. O que são. Universidade Federal de Santa Maria. 2017. Disponível em: <http://coral.ufsm.br/centroserra/index.php/2015-08-17-13-06-33/o-que-sao>. Acesso em 18 jan. 2019.

QUADROS, M. O próximo do território quilombola : a cosmopolítica dos moradores de Júlio Borges. Tese de Doutorado em Sociologia. Porto Alegre: PPGS-UFRGS, 2015.

RUBERT, R. A. Comunidades Negras Rurais do RS: um levantamento sócio-antropológico preliminar. Porto Alegre: RS-Rural/ IICA, 2005.

VATTATHARA, S. D. Mulheres quilombolas e luta por reconhecimento. Trabalho de conclusão de curso. Santa Maria: UFSM, 2018. 